\title{
Pulmonary infiltrates in immunocompromised patients: diagnosis by cytological examination of bronchoalveolar lavage fluid
}

\author{
JENNIFER A YOUNG, JM HOPKIN, WP CUTHBERTSON \\ From the Departments of Pathology and Medicine, Queen Elizabeth Hospital and University of Birmingham, \\ Birmingham
}

SUMMARY Thirty pulmonary infiltrates in 26 patients were investigated by bronchoalveolar lavage. Sixteen of the patients were on therapeutic immunosuppression for renal disease or transplant and 10 had leukaemia, lymphoma, or allied conditions. A rapid specific diagnosis was made in $21(70 \%)$ episodes by cytological examination of the fluid and in $28(93 \%)$ by a combination of cytology and microbiology. No complications from haemorrhage or pneumothorax ensued. Pneumonia due to Pneumocystis carinii was the most common diagnosis (27\%), but opportunistic infections from cytomegalovirus, candida, aspergillus, zygomycetes, and acid fast bacilli were also identified by cytology. Two episodes were caused by occult pulmonary haemorrhage and five patients had malignant infiltration of the lung from leukaemia, myeloma, Hodgkin's disease, and lymphoplasmacytoid lymphoma. In two of these there was also evidence of infection. In seven cases with non-diagnostic cytology infections due to Staphylococcus aureus, Pseudomonas aeruginosa, pneumococcus, micrococcus, and Aspergillus fumigatus were identified on culture. In two patients $(7 \%)$ no specific diagnosis was established by lavage: one had serological evidence of legionella infection and the second had $P$ aeruginosa septicaemia. Twelve $(75 \%)$ of the renal patients and six $(60 \%)$ of those with leukaemia, lymphoma, and allied conditions recovered.

Pulmonary infiltrates in immunocompromised patients are common and have a varied aetiology and a high mortality. ${ }^{2}$ Opportunistic infection is a common cause but must be distinguished from other conditions such as occult haemorrhage, drug or radiation toxicity, malignant disease, and nonspecific interstitial pneumonitis. In addition, if optimum treatment is to be given the pathogenic organism must be identified. Non-invasive investigations are seldom helpful, ${ }^{34}$ and the diagnostic accuracy of biopsy, whether transbronchial or open lung, varies considerably. ${ }^{5}$ Also some doctors are reluctant to advise biopsy in severely ill immunocompromised patients. ${ }^{6}$ Fine needle aspiration of the lung causes fewer serious complications than biopsy but is associated with the same hazards of haemorrhage and pneumothorax. ${ }^{7}$

The technique of bronchoalveolar lavage has been developed for the investigation of interstitial lung disease. ${ }^{89}$ Published reports show it to be a safe ${ }^{10}$

Accepted for publication 24 November 1983 procedure which obtains plentiful cellular material from the lungs. ${ }^{11}$ The purpose of the present study was to assess the value of cytological examination of bronchoalveolar lavage fluid in the investigation of immunocompromised patients with pulmonary infiltrates of unknown aetiology.

\section{Material and methods}

Thirty pulmonary infiltrates in 26 patients were investigated by bronchoalveolar lavage. The patients comprised two groups. Sixteen were from the Department of Nephrology and were receiving therapeutic immunosuppression, 11 after renal transplant and five for kidney disease (rapidly progressive glomerulonephritis, systemic lupus erythematosus, and Goodpasture's syndrome). Ten patients were from the Departments of Haematology and Oncology. These included five patients with leukaemia, one of whom had received a bone marrow transplant, and two patients with aplastic anaemia, one of whom had also undergone bone marrow transplant. There was one patient with 
non-Hodgkin's lymphoma and one with Hodgkin's disease. The remaining patient was an elderly woman who was admitted as an emergency with severe respiratory distress. She was found to have dysglobulinaemia, the cause of which had not been established at the time of bronchoscopy.

The patients who had undergone renal or bone marrow transplant were all receiving either cyclosporin A or prednisolone and azathioprine. The other renal patients were taking prednisolone and cyclophosphamide, and the patients with leukaemia and lymphoma were on a range of therapeutic regimens which included steroids, cytotoxic drugs, and radiotherapy. Both patients who had received bone marrow transplants had undergone total body irradiation. The indications for bronchoalveolar lavage were severe illness, with cough or dyspnoea, and abnormal chest $x$ ray film in patients in whom no specific microbial diagnosis had resulted from examination of sputum (if available) and blood. The patient with Hodgkin's disease had already had a percutaneous fine needle aspiration of the lung, which was non-diagnostic both cytologically and on culture.

The bronchoalveolar lavage were collected during fibreoptic bronchoscopy by the method previously described. ${ }^{12}$ The washings were obtained from the middle lobe or lingula in patients with diffuse radiological infiltrates and as appropriate where the abnormality was localised. Two or three $20 \mathrm{ml}$ aliquots of sterile saline were instilled and aspirated, roughly half of the volume being returned. A sample of fluid was submitted to the Department of Microbiology and the remaining material sent for immediate cytological processing.

The lavage fluid was centrifuged for $5 \mathrm{~min}$ at 3000 rpm and smears were prepared from the deposit. These were stained by the Papanicolaou, MayGrünwald-Giemsa, Ziehl-Neelsen, and Grocott methenamine silver methods. When the pigment laden macrophages were numerous a Perls' stain for haemosiderin was included. If organisms suggestive of nocardia or actinomyces were seen a Gram stain was also carried out. The specimen from the patient with dysglobulinaemia was examined for immuno-

Table 1 Results of bronchoalveolar lavage in 30 episodes

\begin{tabular}{llll}
\hline Result & Cytology & Microbiology & Combined \\
\hline $\begin{array}{l}\text { Diagnostic } \\
\text { Non-diagnostic }\end{array}$ & $21^{*}$ & $13^{*}$ & 28 \\
$\begin{array}{c}\text { Non-specific } \\
\text { abnormality }\end{array}$ & 3 & & \\
$\quad$ No abnormality & 6 & 17 & 1 \\
Total & 30 & 30 & 1 \\
Sensitivity & $70 \%$ & $42 \%$ & 30 \\
\hline
\end{tabular}

${ }^{*}$ Both diagnostic in six episodes. globulins (IgG, IgA, IgM, and kappa and lambda light chains) by the unlabelled antibody peroxidase-antiperoxidase method. ${ }^{13}$ Antisera were obtained commercially from Mercia-Brocades Ltd, West Byfleet, Surrey, England.

The cytology was all reported by one author (JAY). The fluid was examined for the presence of abnormal cells, haemosiderin laden macrophages, acid fast bacilli, and evidence of viral, parasitic, or mycotic infection. Apart from acid fast bacilli, nocardia, and actinomyces, bacteria were not looked for in the cytological specimens.

\section{Results}

The number of specific diagnoses and the sensitivity of cytology, microbiology, and the combined techniques are shown in Table 1. On six occasions a specific diagnosis was made by both cytology and microbiology. Four times this was the same, but on two occasions different aetiological factors were identified. In nine patients the cytology was nondiagnostic, although three displayed non-specific cellular abnormality. Tables 2 and 3 show the findings in the two groups of patients in more detail together with the primary medical condition and eventual outcome.

A definitive diagnosis was made in $21(70 \%)$ of the 30 episodes by cytology. These included 15 opportunistic infections, five cases of malignant infiltration of the lung (in one patient there was cytological evidence of both infection and malignancy), and two episodes of occult pulmonary haemorrhage. In seven patients in whom cytology was non-diagnostic a specific diagnosis resulted from culture, increasing the overall sensitivity to $93 \%$ (28 episodes). In two of the patients who had undergone renal transplant the overall bronchoalveolar lavage results were non-diagnostic. In one of these a retrospective diagnosis of legionella infection was made on serology. The second patient was severely ill with graft rejection and ascites in addition to respiratory distress. The bronchoalveolar lavage was hypercellular and contained, in addition to numerous macrophages, mixed inflammatory cells and large single bizarre cells, which were interpreted as hyperplastic alveolar lining cells. Some of the macrophages contained haemosiderin. These changes were considered consistent with interstitial pneumonitis but no cause was identified. Ferruginous bodies were also found in the fluid, which raised the possibility of pre-existing fibrosis, although there was no known history of exposure to asbestos. This patient did not recover. At necropsy areas of bronchopneumonia coexisted with interstitial pneumonitis. There was oedema, fibrosis, and thick- 
Table 2 Primary medical condition, results of bronchoalveolar lavage, and outcome in 16 patients (18 episodes) from the Department of Nephrology

\begin{tabular}{|c|c|c|c|}
\hline Primary medical condition & Cytology & Microbiology & Outcome \\
\hline $\begin{array}{l}\text { SLE } \\
\text { SLE } \\
\text { Glomerulonephritis (i) } \\
\text { Glomerulonephritis } \\
\text { Goodpasture's syndrome } \\
\text { Renal transplant } \\
\text { Renal transplant } \\
\text { Renal transplant } \\
\text { Renal transplant } \\
\text { Renal transplant (i) } \\
\text { Renal transplant } \\
\text { Renal transplant } \\
\text { Renal transplant } \\
\text { Renal transplant } \\
\text { Renal transplant } \\
\text { Renal transplant }\end{array}$ & $\begin{array}{l}P \text { carini: } \\
P \text { carinii } \\
\text { Cytomegalovirus } \\
\text { Zygomycetes } \\
\text { Haemorrhage } \\
\text { Haemorrhage } \\
P \text { carinii } \\
P \text { carinii } \\
P \text { carinii } \\
P \text { carinii } \\
P \text { carinii } \\
\text { AFB } \\
\text { Candida } \\
- \\
- \\
- \\
\text { Non-specific pneumonitis } \\
-\end{array}$ & $\begin{array}{l}- \\
\overline{-} \\
\text { Mucor } \\
- \\
- \\
- \\
- \\
\overline{-} \\
\bar{M} \text { tuberculosis } \\
C \text { albicans } \\
S \text { aureus } \\
S \text { aureus and } P \text { aeruginosa } \\
\text { Micrococcus } \\
-\end{array}$ & $\begin{array}{l}\text { Recovered } \\
\text { Recovered } \\
\text { Recovered } \\
\text { Died } \\
\text { Recovered } \\
\text { Recovered } \\
\text { Recovered } \\
\text { Recovered } \\
\text { Recovered } \\
\text { Recovered } \\
\text { Recovered } \\
\text { Recovered } \\
\text { Recovered } \\
\text { Died } \\
\text { Died } \\
\text { Recovered } \\
\text { Died* } \\
\text { Recovered } \dagger\end{array}$ \\
\hline
\end{tabular}

${ }^{*} P$ aeruginosa septicaemia.

†Serological evidence of legionella.

$\mathrm{SLE}=$ systemic lupus erythematosus; $\mathrm{AFB}=$ acid fast bacilli.

Table 3 Primary medical condition, results of bronchoalveolar lavage, and outcome in 10 patients (12 episodes) from the Departments of Haematology and Oncology

\begin{tabular}{|c|c|c|c|}
\hline Primary medical condition & Cytology & Microbiology & Outcome \\
\hline AML & Leukaemic infiltration & - & Died \\
\hline ALL (i) & $P$ carinii & 一 & Recovered \\
\hline (iị) & Candida & C albicans & Recovered \\
\hline ALL + BMT & Degeneration & Micrococcus & Recovered* \\
\hline CGL & Leukaemic infiltration & $P$ aeruginosa & Died \\
\hline CLL & Aspergillus & - & Recovered \\
\hline Aplastic anaemia (i) & - & A fumigatus & Recovered \\
\hline (ii) & - & $S$ aureus and $P$ aeruginosa & Died \\
\hline Aplastic anaemia + BMT & Hypereosinophilia & Pneumococcus & Recovered* \\
\hline Hodgkin's disease & Infiltration by Hodgkin's disease & $\bar{n}$ & Recovered \\
\hline Non-Hodgkin's lymphoma & $\begin{array}{l}\text { CMV and infiltration by } \\
\text { lymphoplasmacytoid lymphoma }\end{array}$ & $P$ aeruginosa & Died \\
\hline Hyperglobulinaemia & Infiltration by myeloma & - & Recovered* \\
\hline
\end{tabular}

* Died within six months.

$\mathrm{AML}=$ acute myeloid leukaemia; $\mathrm{ALL}=$ acute lymphoblastic leukaemia; $\mathrm{BMT}=$ bone marrow transplant; $\mathrm{CGL}=$ chronic granulocytic leukaemia; $\mathrm{CLL}=$ chronic lymphocytic leukaemia; $\mathrm{CMV}=$ cytomegalovirus.

ening of the alveolar walls. Pneumocyte hyperplasia, atypia, and desquamation were demonstrated by immunocytochemical staining for epithelial membrane antigen. Pseudomonas aeruginosa was grown from the blood culture.

The most common finding in patients with a definitive diagnosis was opportunistic infection due to Pneumocystis carinii. The eight cases occurred in a cluster shortly after the start of the project. All the patients recovered after treatment with high dose cotrimoxazole. The lavage fluid contained much amorphous debris and few alveolar macrophages. Characteristic cystic forms of $\boldsymbol{P}$ carinii containing one or two comma shaped structures together with small numbers of collapsed empty cysts were identified on the slides stained with Grocott methenamine silver (Fig. 1). Three of these patients had high antibody titres for cytomegalovirus infection but no viral inclusions were found in the bronchoalveolar lavage fluid. Two of the eight patients became ill a second time (tuberculosis and candidiasis) during the study.

Classic "owl's eye" inclusions (Fig. 2) indicating pulmonary cytomegalovirus infection were found in the macrophages from two patients. One of these also had cytological evidence of infiltration of the lung by malignant cells from lymphoplasmacytoid non-Hodgkin's lymphoma in addition to $P$ aeruginosa on culture. This patient died suddenly from myocardial infarction $8 \mathrm{~h}$ after bronchoscopy. The cytological findings were all confirmed at necropsy. The other patient with cytomegalovirus infection, 


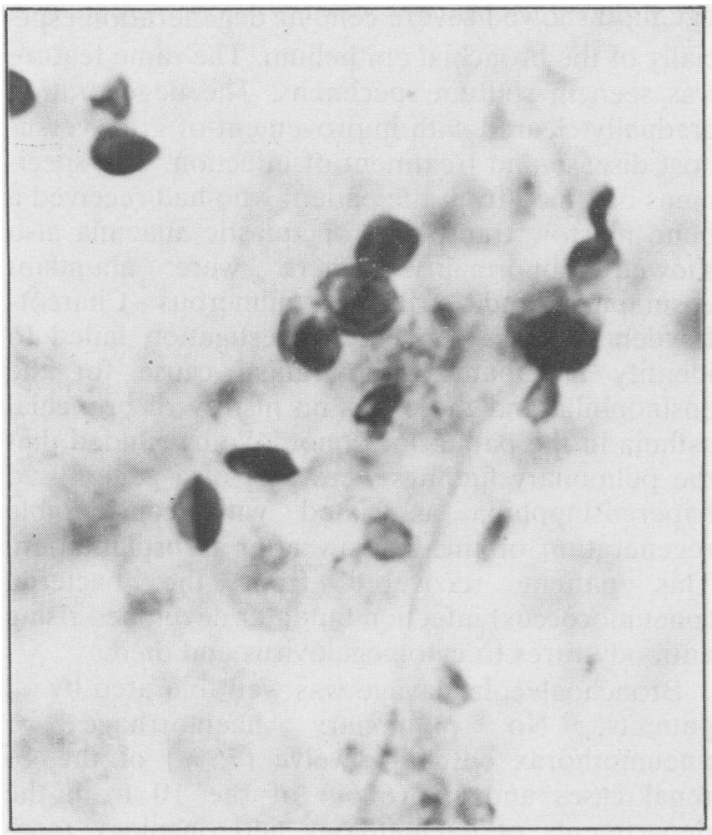

Fig. 1 Cystic forms of Pneumocystis carinii with foamy exudate in background. Grocott methenamine silver $\times$ 1060.

who had rapidly progressive glomerulonephritis, made a slow recovery but died during a second episode of infection (mucormycosis).

Mycotic infections were found either alone or in association with other abnormalities on six occa-

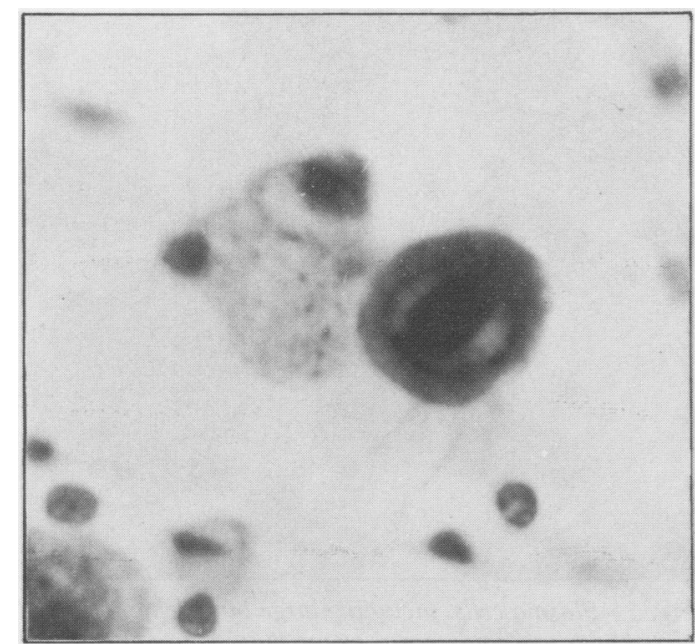

Fig. 2 Cytomegalovirus infection. Macrophage containing intranuclear inclusion body. Papanicolaou $\times 825$.

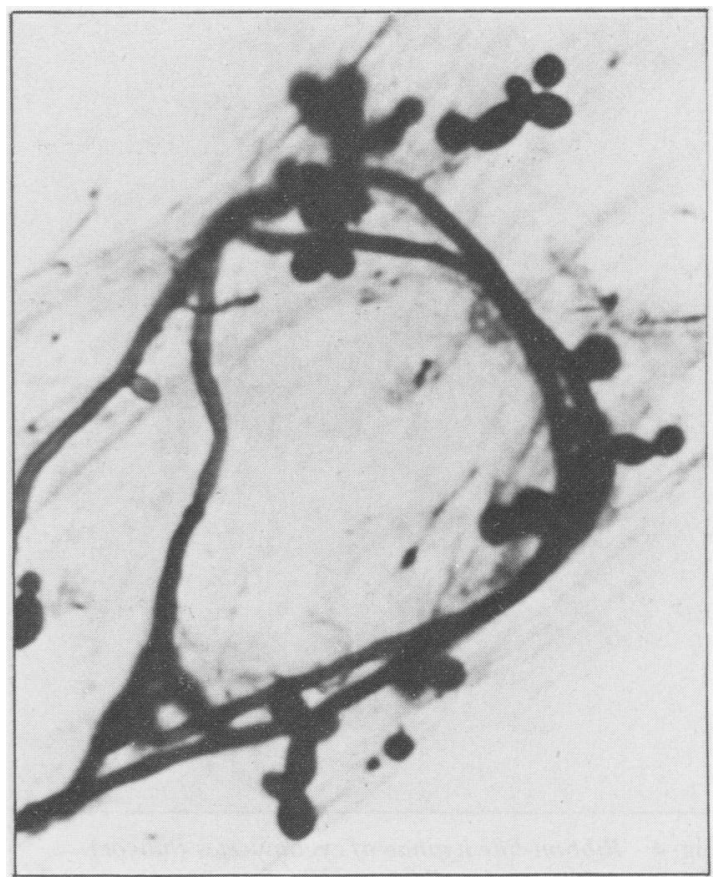

Fig. 3 Pseudohyphae and budding spores of Candida sp. Grocott methenamine silver $\times 825$.

sions. Three were due to candida, two to aspergillus, and one to mucor. Candida generally presents as a mixture of yeast cells (blastoconidia) and filamentous elements, which may be true hyphae or pseudohyphae. Budding spores originating at points of constriction on the filaments are characteristic (Fig. 3). The aspergillus was not seen in the cytological preparations in one of the cases but was found on culture, and in the second instance septate hyphae with dichotomous branching were seen in the fluid but there was no fungal growth on culture. Both these patients recovered after anti-fungal treatment, though one later died from pyogenic infection. Long hyphae, branching at angles up to $90^{\circ}$, were found in one patient and were interpreted as probable zygomycetes (Fig. 4). Speciation from culture confirmed mucormycosis. The infection was fatal.

The two cases of occult pulmonary haemorrhage occurred in patients with Goodpasture's syndrome and rapidly progressive crescentic IgA nephritis. On each occasion the macrophages, when stained by the Papanicolaou technique, were filled with large granules of golden brown pigment. Perls' stain confirmed the presence of haemosiderin.

Malignant infiltration of the lung was diagnosed in five patients. One had acute myeloid leukaemia and 


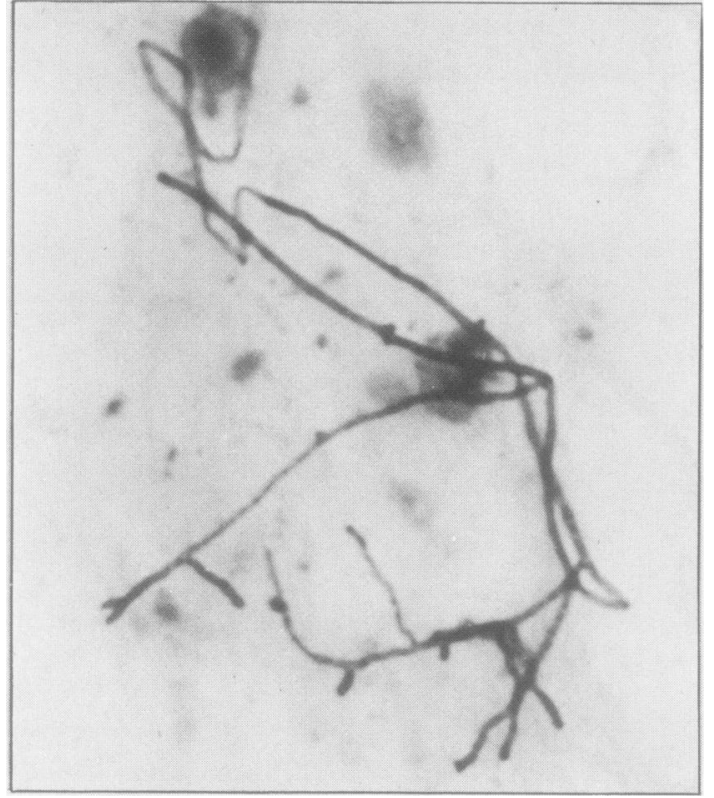

Fig. 4 Ribbon-like hyphae of zygomycetes (mucor). Grocott methenamine silver $\times 330$.

another had chronic granulocytic leukaemia, in whom $P$ aeruginosa was also found. Malignant cells were identified in the fluid from the patient with lymphoplasmacytoid non-Hodgkin's lymphoma, who also had multiple infections (cytomegalovirus, $P$ aeruginosa). In a girl with mediastinal Hodgkin's disease, lymphocytes, Reed-Sternberg cells, and mononuclear Hodgkin's cells were found in the fluid, confirming pulmonary involvement. The elderly woman with dysglobulinaemia was clinically suspected to have pneumocystis infection. The cytological specimens showed a monoclonal (IgG, lambda) proliferation of morphologically abnormal plasma cells, including many unusually large Mott type cells (Fig. 5). There was no evidence of infection. The bronchoalveolar lavage diagnosis of respiratory distress owing to infiltration of the lungs by malignant cells from a plasma cell tumour was substantiated when similar cells were found in the bone marrow. Pulmonary function tests and chest $x$ ray film improved considerably on treatment with melphalan, but she died from myelomatosis four months later.

In two cases with bacterial infections on culture, the cytology, although non-diagnostic, showed cellular abnormality. The patient who had undergone bone marrow transplant had grade $2 / 3$ graft versus host disease at the time of bronchoscopy. The lav- age fluid showed severe cellular degeneration especially of the bronchial epithelium. The same feature was seen in sputum specimens. The degeneration gradually cleared with improvement of graft versus host disease and treatment of infection. The specimens obtained from the patient who had received a bone marrow transplant for aplastic anaemia also showed abnormality. There were abundant eosinophils and strikingly numerous CharcotLeyden crystals. Thorough investigation failed to identify any parasitic or fungal cause for the eosinophilia and there was no history of bronchial asthma in the patient or donor. We concluded that the pulmonary findings were part of a generalised hypereosinophilia associated with considerable regeneration of the marrow after transplantation. This patient recovered from the bacterial (pneumococcus) infection but later developed rising antibody titres to cytomegalovirus and died.

Bronchoalveolar lavage was well tolerated by all patients. No pulmonary haemorrhage or pneumothorax ensued. Twelve $(75 \%)$ of the 16 renal cases and six $(60 \%)$ of the 10 from the departments of haematology and oncology recovered.

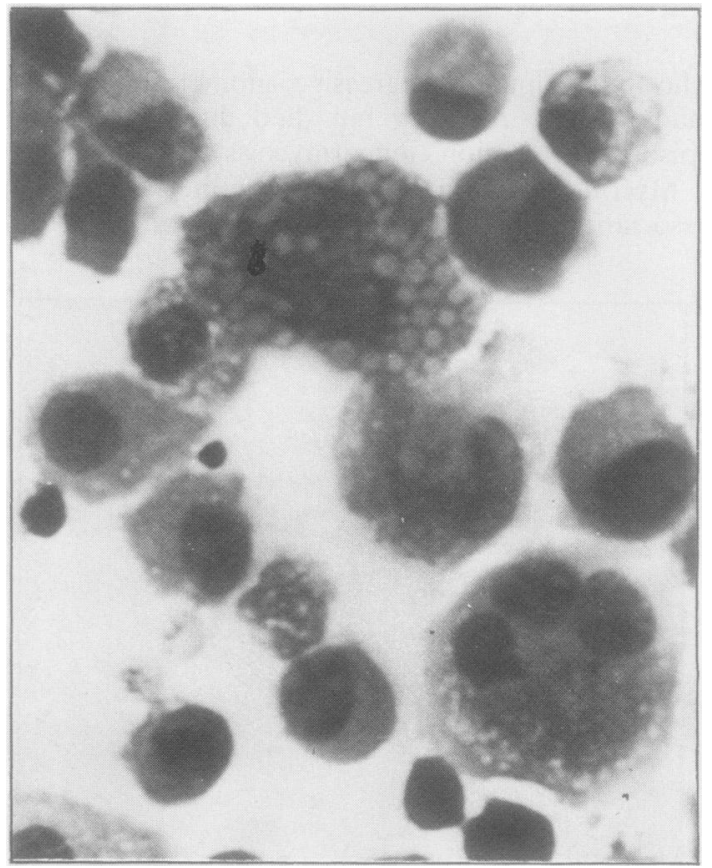

Fig. 5 Plasma cells, including large binucleate Mott cell, mixed with macrophages. Lavage fluid from patient with pulmonary infiltrate due to myelomatosis. May-Grünwald Giemsa $\times 825$. 


\section{Discussion}

The development of a pulmonary infiltrate in an immunocompromised patient is an urgent clinical problem. Arriving at an exact diagnosis is made difficult by the frequently non-specific nature of clinical and radiological findings, the variety of possible causes, and the problem of obtaining adequate representative material from the lungs of severely ill immunosuppressed patients. ${ }^{14}$

A survey of the results of open lung biopsy ${ }^{5}$ found the mean diagnostic yield to be $69 \%$, but in many studies $^{415}$ the percentage of specific diagnoses falls below this figure, though $91 \%$ was achieved by Rosen et $\mathbf{l}^{16}$ in the diagnosis of $P$ carinii. The overall complication rate was $11 \% .^{5}$ Limitations of open lung biopsy include the need for general anaesthetic, delay encountered in organisation, and the reluctance of doctors to use it in patients with recurrent infiltrates. ${ }^{17}$ In eight series of fibreoptic bronchoscopies the mean diagnostic yield from transbronchial biopsy was $41 \%$, from bronchial brushing $27 \%$, and from a combined approach $47 \% .5$ Matthay et al ${ }^{18}$ obtained a diagnosis in $84 \%$ of their cases by the combined use of biopsy and brushing, but the study contained a high incidence of focal carcinoma, which may have augmented the sensitivity. The mean incidence of haemorrhage $(>25 \mathrm{ml})$ and pneumothorax was $7 \%$ for each complication in seven series of bronchoscopies. ${ }^{5}$ Cunningham et al, ${ }^{3}$ however, found that $26 \%$ suffered from haemorrhage and $19 \%$ from pneumothorax. Fewer studies on fine needle aspiration of the lung in immunosuppressed patients have been published, but Sagel et $a l^{19}$ reported a diagnostic rate of $77 \%$ in 31 such patients and Castellino and Blank ${ }^{20}$ achieved a rate of $73 \%$ in 108 infectious episodes. The most common complication is pneumothorax, which occurs in about a quarter of all patients. ${ }^{7}$ Castellino and Blank $^{20}$ reported this complication in $28 \%$, of which $13 \%$ required thoracostomy. The present investigation shows the sensitivity of cytological examination of bronchoalveolar lavage fluid $(70 \%)$ to be comparable to that of published reports on biopsy ${ }^{5}$ and fine needle aspiration ${ }^{19} 20$ in immunosuppressed patients. In contrast, however, there were no complications due to haemorrhage or pneumothorax.

There is increasing recognition of the value of morphological assessment of histological and cytological material for the rapid identification of unusual pathogens, ${ }^{21-23}$ especially $P$ carinii and certain genera of opportunistic viruses and fungi. This can be carried out on the same preparations and at the same time as the evaluation of specimens for non-infectious causes. This is especially valuable in patients who are immunodeficient as a result of malignant disease. Cytology, however, has little to contribute to the diagnosis of bacterial infections. Bronchoalveolar lavage provides abundant material which is suitable for microbiology as well as cytology. By using both techniques on the fluid the sensitivity rate was increased from $70 \%$ to $93 \%$. Two patients had evidence of both neoplastic infiltration of the lung and infection, which emphasises the value of the combined approach to diagnosis. Opportunistic infection was diagnosed by cytology as the cause of the infiltrate in $15(50 \%)$ episodes. In eight instances $(27 \%)$ the pathogen was $P$ carinii. An incidence of $32-38 \%$ has been found in other series, ${ }^{44}$ confirming the increasing importance of this organism as a cause of pneumonia in immunocompromised hosts. $P$ carinii is often associated with cytomegalovirus. ${ }^{25}$ Three of these patients had serological evidence of cytomegalovirus infection but no indication of pulmonary disease in the bronchoalveolar lavage fluid. The specimens from patients with $P$ carinii pneumonia contained much amorphous exudate and only small numbers of alveolar macrophages, which may perhaps have resulted in false negative findings. The patients all recovered after treatment with cotrimoxazole. This is unlikely to have occurred if pulmonary cytomegalovirus was a contributory factor in the respiratory disease. In interpreting cytological specimens stained with Grocott methenamine silver care must be taken not to mistake clusters of fungal spores or artefactual deposition of silver on leucocytes and erythryocytes as $\boldsymbol{P}$ carinii. Adequate control material is essential.

Many viruses produce no specific cytological changes. Several which cause opportunistic respiratory infection are associated with characteristic cytological markers, however, which permit rapid preliminary identification at genus level. In addition to cytomegalovirus, these include, Herpesvirus hominis (Herpes simplex virus), Herpesvirus varicellae (varicella zoster), and adenovirus. While some features produced by cytomegalovirus, herpes simplex virus, and varicella zoster do show overlap, basophilic Cowdry type $\mathrm{A}^{26}$ intranuclear inclusions, intracytoplasmic inclusions, and cytomegaly characterise cytomegalovirus infection. The eosinophilic inclusions, "ground glass" nuclei, and cell fusion with multinucleation and moulding found in herpes simplex virus and varicella zoster are not a feature of cytomegalovirus infection. Basophilic inclusions occur with adenovirus, but these are associated with "smudge" cells, ${ }^{22}$ which are not seen with cytomegalovirus.

Proof of the presence of mycotic infection is ideally established by culture, but this is slow and the fungus may fail to grow. ${ }^{23}$ There are also many 
limiting factors in the use of immunologically specific fluorescent antibody stains. ${ }^{23}$ Preliminary morphological identification using empirical staining methods can therefore be a rapid and valuable aid in patient management. Both candida and aspergillus, however, occur in the upper respiratory tract unassociated with lower respiratory tract infection. Fungal elements which are not closely intermingled with alveolar macrophages should therefore be interpreted with caution. Speciation of candida, aspergillus, and zygomycetes is not satisfactory when based on morphology alone, but identification at genus or class level is adequate for appropriate treatment to be instituted. Culture showed the case of zygomycosis to be due to mucor. Aspergillus was found in two patients, once by cytology and once on culture. Both patients responded to antifungal treatment, confirming the diagnoses and the complementary nature of the investigations.

In two patients, one with Goodpasture's syndrome and the other with rapidly progressive $\operatorname{IgA}$ crescentic glomerulonephritis, no infection was identified, but there was cytological evidence of occult pulmonary haemorrhage. Antimicrobial treatment was withheld, both $x$ ray films cleared, and the patients recovered. Macrophages laden with haemosiderin may also be found in severe pulmonary oedema, but this is clinically diagnosable and responds to diuretics. In the cases of infective pneumonia and also in the patient with pneumonitis and pseudomonas septicaemia smaller numbers of Perls' positive macrophages were present but they did not approach the numbers seen in the two cases with pulmonary haemorrhage.

Five patients had malignant infiltration. The likelihood of this is influenced by the general state of the disease-pulmonary dissemination is unlikely without evidence of advancing malignancy elsewhere. Both patients with leukaemia were in haematological relapse, the patient with Hodgkin's disease had mediastinal node disease, and the patient with lymphoplasmacytoid lymphoma had recurrent lymphadenopathy. The elderly woman with myelomatosis, who presented as an urgent case of respiratory distress, also had widely disseminated disease. Evidence of malignant infiltration of the lung does not, however, preclude the possibility of coexisting infection, as was found in two cases in this series.

Pneumonia accounts for half of the deaths in some transplant programmes, ${ }^{\prime}$ but mortality is highest in the first six months and long term prognosis is generally good if early infection is survived. The potential for recovery is increased by rapid diagnosis and the institution of prompt specific antimicrobial treatment. ${ }^{28}$ This is especially true of infection by $P$ carinii. In the present series the 12 renal patients who survived all remained alive and well at follow up one year later. Six $(60 \%)$ of the patients with leukaemia, lymphoma, and allied conditions recovered. Owing to the nature of their primary disease, however, the long term outlook of this group is much less favourable and at six months survival had fallen to $30 \%$.

As a result of this study, we believe that cytological examination of bronchoalveolar lavage fluid is a safe, rapid, and helpful diagnostic aid in the management of immunocompromised patients with pulmonary infiltrates.

We thank the physicians from the Departments of Nephrology, Haematology, and Oncology, who referred their patients for bronchoscopy and especially Dr D Adu, Dr J Michael, Dr JH Turney, Dr BJ Boughton, and Dr IM Franklin. We gratefully acknowledge the contribution of many members of the Department of Microbiology and thank Dr $J$ Crocker, Dr S Ghosh, and Dr J Simon for postmortem histology, Dr AJ Howie for the immunocytochemical staining for EMA, and Mrs J Cheney for secretarial assistance.

\section{References}

' Ramsay PG, Rubin RH, Tolkoff-Rubin NE, Cosmi AB, Russell PS, Greene R. The renal transplant patient with fever and pulmonary infiltrates: etiology, clinical manifestations, and management. Medicine 1980;59:206-22.

${ }^{2}$ Pennington JE, Feldman NT. Pulmonary infiltrates and fever in patients with hematologic malignancy: assessment of transbronchial biopsy. Am J Med 1977;62:581-7.

${ }^{3}$ Cunningham JH, Zavala DC, Corry RJ, Keim LW. Trephine air drill, bronchial brush and fibreoptic transbronchial lung biopsies in immunosuppressed patients. Am Rev Resp Dis 1977; 115:213-20.

${ }^{4}$ Singer C, Armstrong D, Rosen PP, Walzer PD, Yu B. Diffuse pulmonary infiltrate in immunosuppressed patients: prospective study of 80 cases. Am J Med 1979;66:110-20.

${ }^{5}$ Matthay RA, Moritz ED. Invasive procedures for diagnosing pulmonary infection: a critical review. Clinics in Chest Medicine 1981;2:3-18.

- Anonymous. Pulmonary problems of the immunocompromised patient (Editorial). Br Med J 1981;282:2077.

' Sinner WN. Complications of percutaneous transthoracic needle aspiration biopsy. Acta Rad (Diag) 1976;17:813-28.

${ }^{8}$ Weinberger SE, Kelman JA, Elson NA, et al. Bronchoalveolar lavage in interstitial lung disease. Ann Intern Med 1978;89:459-66.

' Hunninghake CW, Cade JE, Kawanami O, Ferrans VJ, Crystal RG. Inflammatory and immune processes in the human lung in health and disease: evaluation by bronchoalveolar lavage. Am J Pathol 1979;97:149-206.

${ }^{10}$ Strumpf IJ, Feld MK, Cornelius MJ, Keogh BA, Crystal RG. Safety of fibreoptic bronchoalveolar lavage in evaluation of interstitial lung disease. Chest 1981;80:268-71.

"Haslam PL, Turton CWG, Heard B, et al. Bronchoalveolar lavage in pulmonary fibrosis: comparison of cells obtained with lung biopsy and clinical features. Thorax 1980;35:9-18. 
${ }^{12}$ Hopkin JM, Turney JH, Young JA, Adu D, Micheal J. The rapid diagnosis of abscure pneumonia in immunosuppressed renal patients by cytology of alveolar lavage fluid. Lancet 1983;ii: 299-301.

${ }^{13}$ Curran RC, Gregory J. Demonstration of immunoglobulin in cryostat and paraffin sections of human tonsil by immunofluorescence and immunoperoxidase techniques. $J$ Clin Path 1978;31:974-83.

${ }^{14}$ Fanta $\mathrm{CH}$, Pennington JE. Fever and new lung infiltrates in the immunocompromised host. Clinics in Chest Medicine 1981;2:19-39.

is Rossiter SS, Miller DC, Churg AM, Carrington CB, Mark JB Open lung biopsy in the immunosuppressed patient. Is it really beneficial? J Thorac Cardiovasc Surg 1979;77:338-45.

${ }^{16}$ Rosen PP, Martini N, Armstrong D. Pneumocystis carinii pneumonia: diagnosis by lung biopsy. Am J Med 1975;58:794-802.

17 Puksa S, Hutcheon MA, Hyland RH. Usefulness of transbronchial biopsy in immunosuppressed patients with pulmonary infiltrates. Thorax 1983;38:146-50.

${ }^{18}$ Matthay RA, Farmer WC, Odero D. Diagnostic fibreoptic bronchoscopy in the immunosuppressed host with pulmonary infiltrates. Thorax 1977;32:539-45.

${ }^{19}$ Sagel SS, Ferguson TB, Forrest JV, Roper CL, Weldon CS, Clark RE. Percutaneous transthoracic aspiration needle biopsy. Ann Thorac Surg 1978;26:399-405.
${ }^{20}$ Castellino RA, Blank N. Etiologic diagnosis of focal pulmonary infection in immunocompromised patients by fluoroscopically guided percutaneous needle aspiration. Radiology 1979; 132: $563-7$.

${ }^{21}$ Johnston WW, Frable WJ. Diagnostic respiratory cytopathology. New York: Masson Publishing USA, 1979:96-150.

${ }^{22}$ Myerowitz RL. The pathology of opportunistic infections. New York: Raven Press, 1983:23-49.

${ }^{23}$ Schwarz J. The diagnosis of deep mycoses by morphologic methods. Hum Pathol 1982;13:519-33.

${ }^{24}$ Tenholder MF, Hooper RG. Pulmonary infiltrates in leukaemia. Chest 1980; 78:468-73.

${ }^{25}$ Haselton PS, Curry A. Pneumocystis carinii: the continuing enigma (Editorial). Thorax 1982;37:481-5.

${ }^{26}$ Cowdry EV. The problem of intranuclear inclusions in virus diseases. Arch Pathol 1934;18:528-42.

${ }^{27}$ Pennington JE. Aspergillus pneumonia in hematologic malignancy: improvements in diagnosis and therapy. Arch Intern Med 1977;137:769-71.

${ }^{28}$ Rubin RH, Wolfson JS, Cosimi AB, Tolkoff-Rubin NE. Infection in the renal transplant recipient. Am J Med 1981;70:405-11.

Requests for reprints to: Dr Jennifer A Young, Department of Pathology, The Medical School, University of Birmingham, Birmingham B15 2TJ, England. 